\title{
Sero Diagnosis of Tuberculosis in Children Using Two ELISA Kits
}

\author{
Soumya Swaminathan ${ }^{1}$, P. U madevi ${ }^{2}$, S. Shantha ${ }^{3}$, A. Radhakrishnan ${ }^{4}$ \\ and M anjula Datta \\ 1,5 Tuberculosis Research Centre, ICMR Spurtank Road (Mayor Ramanathan Road), \\ Chetput, Chennai and ${ }^{2,4}$ Institute of Social Pediatrics, ${ }^{3}$ Department of Immunology, \\ G overnment Stanley Hospital, Chennai
}

\begin{abstract}
The diagnosis of childhood tuberculosis is based on circumstantial evidence in the absence of a gold standard in the majority of cases. Sero-diagnosis offers scope for an early diagnosis in a variety of clinical conditions and is simple to perform. A number of mycobacterial antigens have been used for antibody detection assays and several are available as kits in the market. This study was done to evaluate the value of antibody detection kits (ELISA) against the A60 antigen and 38kDa antigen of Mycobacterium tuberculosis in the diagnosis of childhood tuberculosis at the outpatient department of the Institute of Social Paediatrics, Government Stanley Hospital in collaboration with Tuberculosis Research Centre, Chennai. Thirty five children with pulmonary tuberculosis, 7 with TB lymphadenitis and 22 healthy controls were studied. In addition to routine investigations including gastric lavage for AFB culture, serum antibodies against the A60 and $38 \mathrm{kDa}$ antigens were assayed using commercially available ELISA kits. With A60, IgM serum levels were positive in $74 \%$ of pulmonary TB cases, $57 \%$ of TB lymphadenitis cases and $50 \%$ of controls. A60 lgG was positive in $17 \%$ of pulmonary TB, $86 \%$ of TB lymphadenitis and $14 \%$ of controls. The $38 \mathrm{kDa}$ IgG antibody was positive in $37 \%$ of pulmonary and $86 \%$ of TB lymphadenitis cases and $27 \%$ of controls. Among 10 culture confirmed cases, A60 lgM was positive in $8, A 60 \operatorname{lgG}$ in 3 and $38 \mathrm{kDa} \operatorname{lgG}$ in 5 patients. The sensitivity of the tests ranged between $29 \%$ and $71 \%$ and specificity between $50 \%$ and $86 \%$. Although the numbers are small, the results suggest that serodiagnosis using the currently available antigens of $M$. tuberculosis is unlikely to be a confirmatory test for tuberculosis in children. (Indian J Pediatr 1999; 66 : 837-842)
\end{abstract}

Key words : Sero-diagnosis; Tuberculosis; Children.

There is no uniform consensus in the diagnosis of tuberculosis in children. In the absence of a gold standard, diagnosis is usually based on a combination of clinical features, chest X-ray findings and tuberculin skin test results ${ }^{1}$. Gastric lavage cultures

Reprint requests : Soumya Swaminathan, Deputy Director, Tuberculosis Research Centre, Indian Council of Medical Research, Spurtank Road, Chetput, Chennai - 600 031, Fax : (044) 8262137 are slow and positive only in $20-30 \%$ of pulmonary tuberculosis cases. Although the BACTEC method is quicker, it is prohibitively expensive for routine use ${ }^{2}$. Molecular biologic techniques like PCR can detect very small amounts of bacterial DNA and could be usefu1 $1^{3,4}$. However, be cause of the extreme sensitivity of the technique, detection of mycobacterial DNA from recently infected children may not distinguish infection from disease. In ex- 
trapulmonary TB, the diagnosis is even more difficult because of lack of tissue specimens, except in TB lymphadenitis.

Serodiagnosis is advantageous because it is easy, relatively inexpensive and results can be obtained easily. Moreover, it offers scope for an early diagnosis in a wide variety of clinical situations ${ }^{5}$. A number of mycobacterial antigens have been used for antibody detection assays but have given varying results and none has been sensitive or specific enough for routine use.

Despite its limitations, serodiagnostic kits for TB are being aggressively marketed and used by medical professionals. Two of these commercially available kits. (AndaTB kit to detect IgG and IgM antibodies to A60 antigen and Pathozyme TB complex kit to detect IgG antibodies to $38 \mathrm{kDa}$ antigen) are evaluated here for their value in the diagnosis of tuberculosis in children.

\section{MATERIALS AND METHODS}

This investigation was part of a larger study to develop diagnostic criteria for tuberculosis in children in which about 2400 children have been enrolled to date.

This study was carried out from July to September 1996 and all the children diagnosed with tuberculosis during that period and those considered free of tuberculosis, who were available for blood collection, were included. Children in the age group I-12 years attending the outpatient department with signs and symptoms suggestive of tuberculosis were evaluated further. Blood counts, Mantoux test, chest X-ray and gastric lavage for AFB (on two consecutive days) were done. Chest X-rays were done for all children and lymph node biopsies in those who had significantly enlarged lymph nodes.
Sixty four children were included in this study and formed three groups :

(A) Healthy controls (22) : children investigated for tuberculosis and found to be normal.

(B) Pulmonary TB (35) : children presenting with respiratory signs and symptoms, diagnosed to have tuberculosis on work up.

(C) TB lymphadenitis (7) : children presenting with a glandular swelling diagnosed to have TB lymphadenitis on biopsy.

The diagnosis of pulmonary TB was based on clinical and radiographic criteria, (persistent X-ray shadows not responding to antibiotics) with or without a history of contact and positive tuberculin test. Gastric lavage cultures (done at Tuberculosis $\mathrm{Re}$ search (entre) were positive for $\mathbf{M}$. tuberculosis in 10 of the 35 patients. The diagnosis of TB lymphadenitis was confirmed by histopathology or bacteriology or both. Children who had no clinical or laboratory evidence of TB were taken as controls. ELISA using two commercially available kits was performed on blood (serum) obtained from all study patients.

(a) Anda TB kit to detect IgG and IgM antibodies to $A 60$ antigen.

(b) Pathozyme-TB complex kit to detect IgG antibodies to $38 \mathrm{KDa}$ antigen.

The cut off level for a positive test was defined as the average optical density (OD) of the low positive control divided by 1.5 and tests results were reported as positive, negative or equivocal (manufacturer's instructions).

\section{RESULTS}

Of the 42 patients with a diagnosis of tu- 
Table 1. Results of Serodiagnostic Tests in TB Patients and Controls

\begin{tabular}{|c|c|c|c|c|c|c|c|}
\hline \multirow[t]{3}{*}{ Group } & \multirow{3}{*}{$\begin{array}{c}\text { No. of } \\
\text { patients }\end{array}$} & \multicolumn{2}{|c|}{ IgM } & \multicolumn{2}{|c|}{ IgG } & \multicolumn{2}{|c|}{ IgG } \\
\hline & & \multicolumn{2}{|c|}{ A 60} & \multicolumn{2}{|c|}{ A 60} & \multicolumn{2}{|c|}{38 kDa } \\
\hline & & No. & $\%$ & No. & $\%$ & No. & $\%$ \\
\hline Control & 22 & 11 & 50 & 3 & 14 & 6 & 27 \\
\hline Pulm. TB & 35 & 26 & & 6 & & 13 & \\
\hline lymphadenitis & 7 & 4 & & 6 & & 6 & \\
\hline Total TB & 42 & 30 & 71 & 12 & 29 & 19 & 45 \\
\hline
\end{tabular}

berculosis, 36 had a Mantoux reaction $\geq 10$ $\mathrm{mm}(86 \%)$. Chest X-ray was abnormal in $35 / 42$ cases (83\%) and sputum/ gastric lavage was positive for $M$. tuberculosis in 10 cases (24\%). Of the 22 healthy controls, Chest X-ray was normal in all of them and Mantoux was positive in 9 (41\%).

Table 1 shows the ELISA sero-positivity among the different study groups according to the kit used. Cases were defined as those with culture or biopsy confirmation as well as those with a clinical diagnosis of tuberculosis who responded to specific anti-TB treatment. This was taken as the gold standard for calculating various statistical parameters.

Table 2 shows the sensitivity, specificity, positive predictive value, false negativity and accuracy of the three tests. It can be seen that there is a reciprocal relationship between the sensitivity and specificity and

Table 2. Results Using Different Antigens

\begin{tabular}{lccc}
\hline Test results & A 60 & A 60 & 38 kD a \\
& I gM & I gG & I gG \\
\hline Sensitivity & $71 \%$ & $29 \%$ & $45 \%$ \\
Specificity & $50 \%$ & $86 \%$ & $73 \%$ \\
Pos. Pred. value & $73 \%$ & $80 \%$ & $76 \%$ \\
False negativity & $52 \%$ & $61 \%$ & $59 \%$ \\
Accuracy & $64 \%$ & $48 \%$ & $55 \%$ \\
\hline
\end{tabular}

none of the tests was adequate in both. The A 60 IgG and 38KDa IgG had sensitivities that were too low while the specificity of the A60 IgM was only $50 \%$. When only the 10 children with bacteriologically confirmed tuberculosis were considered, 8/ 10 had positive titres for $A 60 \mathrm{IgM}, 3 / 10$ for A 60 IgG and 5/ 10 for 38 kDa IgG. Hence even in bacteriologically confirmed cases, these tests were not sensitive enough to pick up all the cases. In the TB lymphadenitis group, however, both the IgG assays were positive in 6 out of 7 cases. Regarding the specificity, considering only the 13 healthy children with negative Mantoux tests (as truly uninfected controls), the specificity of the three tests was $38 \%, 85 \%$ and $54 \%$. The specificity of the tests, therefore, did not improve by taking into account only tuberculin negative controls.

\section{DISCUSSION}

Immunodiagnosis using different antigens from $M$. tuberculosis has been attempted for the past 100 years. There are a number of crude, semipurified and highly purified antigens that have been proposed as useful antigens for diagnosis. The only $M$. tuberculosis specific antigens shown to date are the $38 \mathrm{kDa}$ of Ivanyi ${ }^{6}$ and $14 \mathrm{kDa}^{7}$. Only a small number of monoclonal antibodies are $M$. 
tuberculosis specific (TB 23, 68, 71, 78) ${ }^{6}$. The value of a serodiagnostic test depends on its sensitivity (number of positive tests out of total number of true cases) and specificity (number of negative tests out of the total number of control samples). The development of antibodies to a particular antigen depends on its immunogenecity, dose and duration of exposure and possibly, the genetic make up of the host. Also, with "natural exposure" to environmental mycobacteria, antibodies develop to common mycobacterial antigens that could cross react with the test antigen ${ }^{8}$.

In the present study, an attempt was made to assess the value of 2 commonly available sero diagnostic kits namely the Anda TB kit to detect IgG and IgM antibodies to $A 60$ antigen and the PathozymeTB kit to detect IgG antibodies to the $38 \mathrm{kDa}$ antigen. The results suggest that neither of the two kits exhibit sufficient sensitivity and specificity to be useful for routine diagnostic use. Even the bacteriologically confirmed cases were not uniformly detected by these tests. This suggests that antibodies to these two antigens are not uniformly increased in childhood tuberculosis cases.

Reported studies on serodiagnostic tests for TB in children have given conflicting re sults (Table 3). Turneer et al did not find the anti $A 60 \mathrm{IgM}$ and IgG measurements use ful in the diagnosis of primary TB or mycobacterial adenitis in children ${ }^{9}$. Delacourt et al found that using the anti-A 60 IgG test and a specificity of $98 \%$, a positive serodiagnosis was observed in $68 \%$ of children with clinically active $\mathrm{TB}^{10}$. The IgM test, however, had a low sensitivity of $19 \%$. They also found that the IgG antibody values were influenced by BCG vaccination and age, increasing with both.

Rosen used mycobacterial sonicates but

TABLE 3. Summary of Serodiagnostic Studies in Children

\begin{tabular}{|c|c|c|c|c|}
\hline Reference & Test & Population & Sensitivity & Specificity \\
\hline Delacourt ${ }^{10}$ (1993) & Antigen 60 (IgG) & Pulm. TB & 0.67 & 0.98 \\
\hline Rosen" (1990) & $\begin{array}{l}\text { Mycobacterial } \\
\text { sonicates }\end{array}$ & Pulm. TB & 0.21 & 0.40 \\
\hline Barrera $^{12}$ (1989) & PPD & $\begin{array}{l}\text { Bacteriologically } \\
\text { confirmed cases }\end{array}$ & 0.51 & 0.98 \\
\hline Alde $^{13}$ (1989) & Antigen 5 & $\begin{array}{l}\text { Bacteriologically } \\
\text { confirmed cases }\end{array}$ & 0.85 & 1.00 \\
\hline Turneer $^{9}$ (1994) & Antigen 60 (IgG) & Pulm. TB & 0.14 & 0.95 \\
\hline Seth $^{14}$ (1997) & PPD & $\begin{array}{l}\text { Pulm. Primary } \\
\text { complex }\end{array}$ & 0.86 & 0.92 \\
\hline $\begin{array}{l}\text { Present study } \\
\text { (1997) }\end{array}$ & $\begin{array}{l}\text { A } 60(\operatorname{lgG}) \\
\text { A } 60(\operatorname{lgM}) \\
38 \mathrm{Kda}(\operatorname{IgG})\end{array}$ & Pulm. TB & $\begin{array}{l}0.29 \\
0.71 \\
0.45\end{array}$ & $\begin{array}{l}0.86 \\
0.50 \\
0.73\end{array}$ \\
\hline
\end{tabular}


sensitivity and specificity were poor, essentially due to cross reactivity with $\mathrm{BCG}^{11}$. Barrera et al had better results using purified protein derivative and showing a specificity of $98 \%$ and a sensitivity of $51 \%$ in bacteriologically confirmed cases $^{12}$. The best results were obtained by Alde et al using antigen 5 which is the same as the $38 \mathrm{kDa}$ antigen ${ }^{13}$. They found a specificity of $100 \%$ and sensitivity of $85.7 \%$ in bacteriologically confirmed tuberculous children but the number of control subjects was low in that study.

In children, antibody levels to $M$. tuberculosis antigens are generally lower than in adults. Such a hyporesponsiveness could be due to the nature of exposure, extent of disease, immunocompetence and genetic background of the children ${ }^{15}$. The presence of cross reacting antibodies also depends on the environment the child lives in. Hence, studies done in one part of the world may not be applicable elsewhere. The issue of reliability of the commercially available serodiagnostic kits can be answered only by testing children in whom the diagnosis has been confirmed. In this study, the kits tested did not diagnose all those children in whom TB was bacteriologically confirmed. At the same time the kits gave positive results in a significant number of healthy (control) children. Hence, they cannot be recommended for routine diagnostic use.

\section{CONCLUSION}

Sero diagnosis requires further development and prospective evaluation. An optimal combination of antigenic epitopes in assay may offer the best prospect of a good diagnostic test for tuberculosis.

\section{Acknowledgements}

The authors wish to thank the staff of the Bacteriology Department of Tuberculosis Research Centre for undertaking mycobacterial cultures. We are grateful to the Director, Institute of Social Pediatrics and Director, TRC for permitting us to do this study. The secretarial help rendered by Shri TM Kasinathan and Smt K Saroja is gratefully acknowledged.

\section{REFEREN CES}

1. Starke JR. Current concepts of epidemiology, diagnosis, treatment of childhood TB in United States. Ind Pediatr 1991; 28 : 335355.

2. Middlebrook G, Reggiardo Z, Tigertt WD. Automated radiometric detection of growth of $M$. tuberculosis in selective media. Am Rev Respir Dis 1977; 1066-1069.

3. Pierre $C$, Oliver $C$, Lecossier $D$ et al. Diagnosis of primary tuberculosis in children by amplification and detection of mycobacterial DNA. Am Rev Respir Dis 1993; $147:$ 420-424.

4. Delacourt C, Poveda JD, Chureau C et al. Use of polymerase chain reaction for improved diagnosis of tuberculosis in children. ] Pediatr 1995; 126 : 703-709.

5. Bothamley GH. Serological diagnosis of tuberculosis. Eur Respir J 1995; 8 (suppl. 20) : 676S-688S.

6. Ivanyi J, Sharp K, Jackett P, Bothamley G. Immunological study of the defined constituents of mycobacteria. Springer Semin Immunopathol 1988; $10: 279-300$.

7. Verbon A, Harskeeri RA, Schuitema A. Characterisation of $M$. tuberculosis $14 \mathrm{k}$ antigen. J Bacteriol 1992; 174 : 1352-1359.

8. Hussey G, Kibel M, Dempster W. The serodiagnosis of tuberculosis in children an evaluation of ELISA test using IgG antibodies to $M$. tuberculosis strain H37RV. Ann Trop Pediatr 1991; 11 : 113-118.

9. Turneer $M, V$ anN erom $E, N$ yafenda J, Waelbroeck A, Duvivier $A$ and Toppet $M$. Determination of humoral immunoglob- 
ulins $M$ and $G$ directed against mycobacterial antigen 60 failed to diagnose primary tuberculosis and mycobacterial adenitis in children. Am J Respir Crit Care M ed 1994; 150 : 1508-1512.

10. Delacourt C, Gobin J, Gaillard J, de Blic J. Value of ELISA using Antigen 60 for the diagnosis of tuberculosis in children. Chest 1993; 104 : 393-398.

11. Rosen EU. The diagnostic value of an enzyme-linked immunosorbent assay using absorbed mycobacterial sonicates in children. Tubercle 1993; 71 : 127-30.

12. Barrera L, Kiceli I, Ritaco V, Torrea B, Broglia B, Botta R et al. Detection of circulating antibodies to purified protein derivative by enzyme-linked immunosorbent assay : its potential for the rapid diagnosis of tuberculosis. Pediatr Infect $D$ is J 1989; 8 : 763-67.

13. Alde SLM, Pinasco HM, Pelosi FR, Budani HF, Palma-Beltran OH, Gonzale Z, Montaner LJ. Evaluation of an enzymelinked immunosorbent assay (ELISA) using an IgG antibody to Mycobacterium tuberculosis Antigen 5 in the diagnosis of active tuberculosis in children. Am Rev Respir Dis 1989; 139 : 748-51.

14. Seth V. In : V. Seth (ed). Essentials of Tuberculosis in Children. Jaypee Brothers 1997; 205-221.

15. Mahadevan S. Serodiagnosis of tubercular infection. Indian Pediatr 1997, 34 : 385388. 